\title{
Need for Testing and Supplementation of Vitamin D3 After Release of COVID-19 Lockdown in Patients with Increased Musculoskeletal Pain
}

\author{
Sarvdeep Singh Dhatt ${ }^{1}$. Vishal Kumar ${ }^{1}$ - Deepak Neradi ${ }^{1}$. Praveen Sodavarapu ${ }^{1}$. Tensubam Tomthin Meetei ${ }^{1}$. \\ Vijay Goni ${ }^{1}$ (i)
}

Received: 24 September 2020 / Accepted: 3 February 2021 / Published online: 6 March 2021

(c) Indian Orthopaedics Association 2021

\begin{abstract}
Aims To evaluate vitamin D3 levels in patients who presented with increased musculo-skeletal pain after release of lockdown period when compared to pre-lockdown status.

Introduction During this COVID pandemic, many countries have implemented lockdown measures and people have to work from home and many students and workers have to restrict themselves to home. During this period, their outdoor activities were limited. After the partial release of this lockdown many of them started to have some kind of physical activity and started experiencing body pains. We evaluated such patients for vitamin D3 levels and symptoms of fibromyalgia.

Methods This is a retrospective analysis of patients from age group 18-60 presented to outpatient department or on telephonic consultation after partial release of lockdown. All patients who had mild back ache before lockdown and had symptoms exaggerated during this lockdown release were included. All patients were investigated for vitamin D3, PTH, thyroid profile, liver functional and kidney functional tests.

Results Out of 120 patients presented to us in a period of 3 months, 31 patients had increased symptoms when compared to pre-lockdown status. 20 out of 31 patients had low vitamin D3 levels. 14 patients also developed symptoms of fibromyalgia. Conclusion There might be many reasons for increased pain during lockdown, but we focussed specially only on vitamin D3 because of its association with increased symptoms of COVID-19. This is a gentle reminder to test for vitamin D3 levels and supplement if found deficient.
\end{abstract}

Keywords Lockdown $\cdot$ vitaminD3 $\cdot$ Fibromyalgia $\cdot$ Covid19 $\cdot$ Severity

\section{Introduction}

Vijay Goni
vijaygoni@gmail.com
Sarvdeep Singh Dhatt
sdhatt@yahoo.com
Vishal Kumar
drkumarvishal@gmail.com
Deepak Neradi
n.deepak47@gmail.com
Praveen Sodavarapu
praveen.omc.2k8@gmail.com
Tensubam Tomthin Meetei
tom.tensubam@gmail.com
Department of Orthopedics, PGIMER, Chandigarh, India
Coronavirus is a type of virus that primarily involves respiratory system, spread through animal transmission to the humans. This novel coronavirus (COVID-19) has emerged newly after Severe acute respiratory syndrome (SARS) and Middle East respiratory syndrome coronavirus (MERS$\mathrm{CoV}$ ) have appeared in the last 20 years $[1,2]$. On 30 January 2020, COVID-19 was considered to be a public health emergency of worldwide concern. First detected in Wuhan, China in December 2019, this animal-related pathogen has spread from China to several other countries causing a global pandemic, forcing more than 100 countries worldwide to implement full or partial nationwide lockdown, [3]. These measures, aimed at limiting social contact to decrease the spread of infection, has forced more than 4 billion people to quarantine themselves at home [4]. Such outbreak 
and subsequent lockdown have resulted in multiple consequences, one of which is related to Vitamin D levels.

Since the recognition of COVID crisis, many regions across the world have taken measures to reduce mobility and advocated lockdown to achieve social distancing, as person-to-person transmission can occur during close exposure to a person infected with the virus that causes COVID-19. Such measures, although necessary, has raised another problem to tackle in terms of vitamin D deficiency. Endogenous production of vitamin D following exposure of skin to ultraviolet rays from sunlight is the major source of this vitamin. As the presence of vitamin $\mathrm{D}$ in natural foods is low and consumption of vitamin $\mathrm{D}$ fortified foods is less, reduction of sun exposure over long time has likely resulted in increased burden of such problem globally. Vitamin D deficiency has a role to play in bone biology, immunity, cell growth, inflammation as well as neuromuscular functions [5-8]. Also, multiple studies have advocated role of vitamin D deficiency in COVID-19 severity and mortality [9-16]. In addition to its probable role to COVID, vitamin D deficiency has been associated with fatigue, muscle pain and weakness, together included under fibromyalgia syndrome $[17,18]$. After the partial release of this lockdown, many citizens have increased their physical activity and subsequently complained of body pains, which has an association with Vitamin D levels. Hence a retrospective evaluation of patients was done to assess the level of vitamin $\mathrm{D}$ in patients, who presented with increased body pain not specific to any trauma.

\section{Methods}

We did a retrospective analysis conducted at PGIMER, Chandigarh. All follow-up patients presented to spine clinic after release of lockdown were evaluated via teleconsultation. All patients who had mild back ache before lockdown and had symptoms exaggerated during this lockdown release were included. Age group of the patients included was 18-60 years. All the patients were homebound during these lockdown period and started to have some sort of activity after the release of lockdown. All patients were evaluated for LFT, RFT, Vitamin D3 $(\mathrm{ng} / \mathrm{ml})$ and PTH levels as it is a routine procedure, we do every 6 months in our follow-up patients. Patients were also investigated for signs of fibromyalgia. A detailed questionnaire was made and data recorded after consulting telephonically. Widespread pain index and symptoms score were noted.

\section{Results}

After release of the lockdown, we attended almost 120 patients telephonically out of which 74 patients were follow-up cases. Most of the follow-up patients are having same complaints and consulted for repeat medications. All patients are home bound during a lockdown period of 6 months. 31 patients had exaggeration of their symptoms after this lockdown when compared to pre-lockdown status. All these 31 patients were included in our study and evaluated for vitamin D3 levels and fibromyalgia scores. Out of 31 patients 20 were male and 11 were female. Mean age of the included patients was 36.9 years range 18-59. Most of the patients included were doing some kind of activity before lockdown and were restricted themselves to home during lockdown. Post lockdown symptoms were exaggerated as they started their activity again. 20 patients had low vitamin D levels and 14 patients had symptoms of fibromyalgia. Vitamin D3 levels were considered low if levels are less than $12 \mathrm{ng} / \mathrm{ml}$ or $30 \mathrm{nmol} / \mathrm{l}$ (Table 1 ).

\section{Discussion}

Recent COVID crisis has sparked interest regarding the role of vitamin D in several aspects related to COVID infection. Studies have proposed that deficiency of vitamin D may weaken the respiratory immune function and can be associated with severe COVID-19 infection [9]. In addition, several studies have attempted to ascertain any relationship between vitamin D deficiency and COVID19 morbidity and death. These studies suggest the role of vitamin $\mathrm{D}$ in preventing viral multiplication and cause immunomodulation to decrease inflammatory damage in COVID-19 infection [10-18, 20]. A recent study in the United States has showed that both sunlight and vitamin D in combination can be related to reduced risk of infection and death by COVID-19 [17].

Although the role of Vitamin D in COVID-19 infection is still being ascertained, its prominent role in the musculoskeletal system and the negative impact of Vitamin D deficiency on bone health is already established. Its importance in the physiology of bone and prevention of rickets, osteomalacia, primary as well as secondary osteoporosis and musculoskeletal pain has been studied and reported in the literature [21].

Sun exposure is required to convert 7-dehydrocholesterol to cholecalciferol in skin, which further undergoes hydroxylation in liver and kidney to become active form of vitamin D, Calcitriol [22]. Decreased exposure to sunlight over long period of time due to the imposed lockdown 
Table 1 Table showing patient details

\begin{tabular}{|c|c|c|c|c|c|c|c|c|}
\hline SL no. & Age & Sex & Occupation & $\begin{array}{l}\text { VIT-D standard range } \\
(\mathrm{ng} / \mathrm{ml})(11.1-42.9)\end{array}$ & Low vitamin $\mathrm{D}$ & WPI score & $\begin{array}{l}\text { Symptom } \\
\text { score }\end{array}$ & $\begin{array}{l}\text { Overall } \\
\text { firbromyalgia } \\
\text { score }\end{array}$ \\
\hline 1 & 55 years & M & Cloth merchant & 16.1 & No & 3 & 3 & No \\
\hline 2 & 59 years & $\mathrm{F}$ & Housewife & 7.8 & Yes & 3 & 2 & No \\
\hline 3 & 53 years & $\mathrm{F}$ & Housewife & 21.9 & No & 2 & 5 & No \\
\hline 4 & 45 years & $\mathrm{F}$ & House maid & 10.9 & Yes & 7 & 6 & Yes \\
\hline 5 & 22 years & $\mathrm{F}$ & Student & 3.00 & Yes & 7 & 5 & Yes \\
\hline 6 & 28 years & M & Pvt company manager & 3.00 & Yes & 8 & 6 & Yes \\
\hline 7 & 38 years & M & HR in pvt company & 3.00 & Yes & 7 & 6 & Yes \\
\hline 8 & 32 years & M & Cloth merchant & 14.1 & No & 2 & 2 & NO \\
\hline 9 & 48 years & M & House wife & 7.47 & Yes & 7 & 7 & Yes \\
\hline 10 & 18 years & $\mathrm{F}$ & Student & 11.0 & Yes & 7 & 5 & Yes \\
\hline 11 & 24 years & $\mathrm{F}$ & Boutique & 6.70 & Yes & 8 & 5 & Yes \\
\hline 12 & 19 years & M & Student & 5.32 & Yes & 3 & 4 & No \\
\hline 13 & 40 years & M & Labourer & 3.57 & Yes & 3 & 3 & No \\
\hline 14 & 22 years & M & Mason & 24.3 & No & 2 & 2 & No \\
\hline 15 & 43 years & $\mathrm{F}$ & Teacher & 9.9 & Yes & 8 & 5 & Yes \\
\hline 16 & 26 years & M & Salesman & 18.6 & No & 2 & 1 & No \\
\hline 17 & 28 years & M & Pharma business & 6.3 & Yes & 7 & 5 & Yes \\
\hline 18 & 18 years & M & Student & 33.9 & No & 2 & 1 & No \\
\hline 19 & 52 years & M & Unemployed & 5.3 & Yes & 2 & 2 & No \\
\hline 20 & 25 years & M & Labour & 26.5 & No & 5 & 3 & No \\
\hline 21 & 38 years & M & Hotel management & 10.7 & yes & 3 & 0 & No \\
\hline 22 & 26 years & M & Driver & 51.6 & No & 3 & 1 & No \\
\hline 23 & 50 years & M & Govt. employee & 8.8 & Yes & 2 & 0 & No \\
\hline 24 & 18 years & M & Student & 25.7 & No & 3 & 1 & No \\
\hline 25 & 33 years & $\mathrm{F}$ & House wife & 5.5 & Yes & 7 & 5 & Yes \\
\hline 26 & 56 years & $\mathrm{F}$ & House wife & 24 & No & 2 & 1 & No \\
\hline 27 & 55 years & M & Mechanic & 8.81 & Yes & 3 & 2 & No \\
\hline 28 & 46 years & M & Merchant & 10.1 & Yes & 7 & 7 & Yes \\
\hline 29 & 56 years & M & Fire service work & $22.8 \mathrm{nmol} / \mathrm{l}(30-100)$ & Yes & 7 & 5 & Yes \\
\hline 30 & 46 years & $\mathrm{F}$ & Teacher & $24.5 \mathrm{nmol} / \mathrm{l}(30-100)$ & Yes & 7 & 5 & Yes \\
\hline 31 & 26 years & $\mathrm{F}$ & IT profession & $20.5 \mathrm{nmol} / \mathrm{l}(30-100)$ & Yes & 13 & 5 & Yes \\
\hline
\end{tabular}

can be a crucial factor in low Vitamin D levels in our patients. A study in individuals with Fitzpatrick skin type $\mathrm{V}$ (brown) in UK has shown that these individuals need at least 25 min of daily sunlight in the afternoon from March to September, to have adequate Vitamin D levels [23]. Hence, Imposition of lockdown with decreased mobility of people has most probably decreased the required amount of sun exposure for vitamin D production all over the world. Such unforeseen circumstances may be continued in the near future, further hampering the well-being of people already overburdened by the pandemic. 14 patients included in our assessment were also experienced symptoms of fibromyalgia, which can be attributed to levels of vitamin D3.
Hence Vitamin D supplementation should be considered in all, and especially in countries where mobility of people has been restricted severely during this worldwide phenomenon to maintain optimal levels in blood and promote musculoskeletal health and probable protective immunity against the Covid-19 infection.

Supplementary Information The online version contains supplementary material available at https://doi.org/10.1007/s43465-021-00376-8.

Funding None.

\section{Compliance with Ethical Standards}

Conflict of interest All authors declare that there are no conflicts of interests. 
Ethical standard statement This article does not contain any studies with human or animal subjects performed by the any of the authors.

Informed consent Informed consent was taken from all patients

\section{References}

1. Ramadan, N., \& Shaib, H. (2019). Middle East respiratory syndrome coronavirus (MERS-CoV): A review. Germs, 9, 35-42.

2. Zhong, N. S., Zheng, B. J., Li, Y. M., Poon, Xie, Z. H., Chan, K. H., et al. (2003). Epidemiology and cause of severe acute respiratory syndrome (SARS) in Guangdong, People's Republic of China, in February, 2003. Lancet, 362, 1353-1358.

3. Dunford, D., Dale, B., Stylianou, N., Lowther, E., Ahmed, M., \& de la Torre Arenas I. (2020). Coronavirus: The world in lockdown in maps and charts. https://www.bbc.com/news/world-52103747. Accessed 19 June 2020.

4. Sidor, A., \& Rzymski, P. (2020). Dietary choices and habits during COVID-19 lockdown: Experience from Poland. Nutrients, 12(6), 1657. https://doi.org/10.3390/nu12061657.

5. Wacker, M., \& Holick, M. F. (2013). Vitamin D—Effects on skeletal and extraskeletal health and the need for supplementation. Nutrients, 5, 111-148.

6. Gendelman, O., Itzhaki, D., Makarov, S., Bennun, M., \& Amital, H. (2015). A randomized double-blind placebo-controlled study adding high dose vitamin $\mathrm{D}$ to analgesic regimens in patients with musculoskeletal pain. Lupus, 24, 483-489.

7. Heath, K. M., \& Elovic, E. P. (2006). Vitamin D deficiencyImplications in the rehabilitation setting. American Journal of Physical Medicine and Rehabilitation, 85, 916-923.

8. Shinchuk, L., \& Holick, M. F. (2007). Vitamin D and rehabilitation: Improving functional outcomes. Nutrition in Clinical Practice, 22, 297-304.

9. Watkins, J. (2020). Preventing a covid-19 pandemic. London: British Medical Journal Publishing Group.

10. Daneshkhah, A., Agrawal, V., Eshein, A., Subramanian, H., Roy, H. K., \& Backman, V. (2020). The possible role of vitamin D in suppressing cytokine storm and associated mortality in COVID19 patients [preprint]. Infectious Diseases (Except HIV/AIDS). https://doi.org/10.1101/2020.04.08.20058578.

11. Darling, A. L., Ahmadi, K. R., Ward, K. A., Harvey, N. C., Couto Alves, A., Dunn-Waters, D. K., et al. (2020). Vitamin D status, body mass index, ethnicity and COVID-19: Initial analysis of the first-reported UK Biobank COVID-19 positive cases (n 580) compared with negative controls (n 723) [preprint]. Infectious Diseases (Except HIV/AIDS). https://doi. org/10.1101/2020.04.29.20084277.
12. De Smet, D., De Smet, K., Herroelen, P., Gryspeerdt, S., \& Martens, G. A. (2020). Vitamin D deficiency as risk factor for severe COVID-19: A convergence of two pandemics [preprint]. Infectious Disease (Except HIV/AIDS). https://doi. org/10.1101/2020.05.01.20079376.

13. Glicio, E. J. (2020). Vitamin D level of mild and severe elderly cases of COVID-19: A preliminary report. Available at SSRN: https://ssrn.com/abstract=3593258.

14. Hastie, C. E., Mackay, D. F., Ho, F., Celis-Morales, C. A., Katikireddi, S. V., Niedzwiedz, C. L., et al. (2020). Vitamin D concentrations and COVID-19 infection in UK Biobank. Diabetes and Metabolic Syndrome: Clinical Research and Reviews, 14, 561-565.

15. Ilie, P. C., Stefanescu, S., \& Smith, L. (2020). The role of vitamin $\mathrm{D}$ in the prevention of coronavirus-Disease 2019 infection and mortality. Aging Clinical and Experimental Research. https://doi. org/10.1007/s40520-020-01570-8.

16. Lau, F. H., Majumder, R., Torabi, R., Saeg, F., Hoffman, R., Cirillo, J. D., et al. (2020). Vitamin D insufficiency is prevalent in severe COVID-19 [preprint]. Infectious Diseases (Except HIV/ AIDS). https://doi.org/10.1101/2020.04.24.20075838.

17. Padhi, S., Suvankar, S., Panda, V. K., Pati, A., \& Panda, A. K. (2020). Lower levels of vitamin D are associated with SARS$\mathrm{CoV}-2$ infection and mortality in the Indian population: An observational study. International Immunopharmacology, 88, 107001. https://doi.org/10.1016/j.intimp.2020.107001.

18. Raharusun, P., Priambada, S., Budiarti, C., Agung, E., \& Budi, C. (2020). Patterns of COVID-19 mortality and vitamin D: An Indonesian study. SSRN Journal. https://doi.org/10.2139/ssrn.35855 61.

19. Prentice, A. (2008). Vitamin D deficiency: A global perspective. Nutrition Reviews, 66, 153-164.

20. Teymoori-Rad, M., Shokri, F., Salimi, V., \& Marashi, S. M. (2019). The interplay between vitamin D and viral infections. Reviews in Medical Virology, 29, e2032.

21. Wintermeyer, E., Ihle, C., Ehnert, S., et al. (2016). Crucial role of vitamin D in the musculoskeletal system. Nutrients, 8(6), 319. https://doi.org/10.3390/nu8060319.

22. Wacker, M., \& Holick, M. F. (2013). Sunlight and Vitamin D: A global perspective for health. Dermato Endocrinology, 5(1), 51-108. https://doi.org/10.4161/derm.24494.

23. Webb, A. R., Kazantzidis, A., Kift, R. C., Farrar, M. D., Wilkinson, J., \& Rhodes, L. E. (2018). Colour counts: Sunlight and skin type as drivers of vitamin D deficiency at UK latitudes. Nutrients, 10(4), 457. https://doi.org/10.3390/nu10040457.

Publisher's Note Springer Nature remains neutral with regard to jurisdictional claims in published maps and institutional affiliations. 